\title{
CDISC SDTM Anti-Viral Outcome of Treatment Terminology
}

National Cancer Institute

\section{Source}

National Cancer Institute. CDISC SDTM Anti-Viral Outcome of Treatment Terminology. NCI Thesaurus. Code C120521.

Terminology associated with the anti-viral outcome of treatment codelist of the Clinical Data Interchange Standards Consortium (CDISC) Study Data Tabulation Model (SDT M). 